\title{
Doses de fósforo no estabelecimento de capim-xaraés e estilosantes Mineirão em consórcio
}

\author{
Jalison Lopes ${ }^{1}$, Antônio Ricardo Evangelista ${ }^{2}$, José Cardoso Pinto ${ }^{2}$, Domingos Sávio \\ Queiroz $^{3}$, Joel Augusto Muniz ${ }^{4}$
}

\author{
1 Programa de Pós-graduação em Zootecnia - UFLA. Bolsista do CNPq. \\ 2 Departamento de Zootecnia - UFLA. \\ ${ }^{3}$ Epamig - Zona da Mata. \\ ${ }^{4}$ Departamento de Ciências Exatas - UFLA
}

RESUMO - Objetivou-se avaliar o efeito da aplicação de fósforo na implantação de estilosantes Mineirão em consórcio com capim-xaraés. O experimento foi instalado em uma área de $8.000 \mathrm{~m}^{2}$, dividida em 24 parcelas experimentais de $333,3 \mathrm{~m}^{2}$. As doses de fósforo utilizadas no estabelecimento da pastagem foram 25, 50, 100 e $200 \mathrm{~kg} / \mathrm{ha}$ de $\mathrm{P}_{2} \mathrm{O}_{5}$. As avaliações foram feitas aos 65 dias após a semeadura. Utilizou-se o delineamento em blocos casualizados com três repetições e duas repetições do tratamento dentro de cada bloco. As maiores taxas de aumento no comprimento da lâmina foliar e perfilhamento do capim-xaraés, comprimento de folíolo, largura de folíolo e altura do estilosantes Mineirão foram observadas com a aplicação de 25 a $50 \mathrm{~kg} /$ ha de $\mathrm{P}_{2} \mathrm{O}_{5}$. As maiores taxas de aumento na largura da lâmina foliar e altura de perfilho do capim-xaraés foram obtidas com aplicação de 25 a $100 \mathrm{~kg} /$ ha de $\mathrm{P}_{2} \mathrm{O}_{5}$. O número de plantas de estilosantes Mineirão foi maior com a aplicação de $44 \mathrm{~kg} /$ ha de $\mathrm{P}_{2} \mathrm{O}_{5}$ e reduziu de forma acentuada com o aumento da adubação fosfatada. A adubação fosfatada de estabelecimento de $44 \mathrm{~kg} / \mathrm{ha}$ de $\mathrm{P}_{2} \mathrm{O}_{5}$ garante maior população inicial de plantas de estilosantes Mineirão em consórcio com o capim-xaraés. Todavia, mais estudos são necessários para se verificar o grau de compatibilidade entre as duas espécies e a viabilidade da consorciação. A aplicação de doses crescentes de fósforo em consórcio proporciona aumento nas taxas de acúmulo de matéria seca do capim-xaraés e de acúmulo de matéria seca total durante o primeiro período seco pós-estabelecimento da pastagem.

Palavras-chave: Brachiaria brizantha, pasto consorciado, perfilhamento, Stylosanthes guianensis

\section{Phosphorus rates in the establishment of intercropping of Xaraés grass and Mineirão stylo}

\begin{abstract}
The objective of this study was to evaluate the effect of the application of phosphorus on the establishment of Stylosanthes guianensis cv. Mineirão and Brachiaria brizantha cv. Xaraés mixed. The experiment was installed in an area of $8,000 \mathrm{~m}^{2}$, divided into 24 plots of $333.3 \mathrm{~m}^{2}$. The phosphorus doses utilized in the establishment of pasture were 25,50 , 100 and $200 \mathrm{~kg} / \mathrm{ha}$ of $\mathrm{P}_{2} \mathrm{O}_{5}$. The evaluations were made 65 days after sowing. The experimental design was a randomized blocks design with three replications and the treatment with two replicates per block. The highest rates of increase in the length of the leaf blade and tillering of Xaraés grass, leaflet length, leaflet width and height of the legume occurred from 25 to $50 \mathrm{~kg} / \mathrm{ha}$ of $\mathrm{P}_{2} \mathrm{O}_{5}$. The highest rates of increase in the width of the leaf blade and tiller height of Xaraés grass occurred from 25 to $100 \mathrm{~kg} / \mathrm{ha}$ of $\mathrm{P}_{2} \mathrm{O}_{5}$. Number of plants of Mineirão stylo was higher with fertilization with $44 \mathrm{~kg} / \mathrm{ha}$ of $\mathrm{P}_{2} \mathrm{O}_{5}$ and decreased drastically with phosphate. Phosphate fertilizers establishing $44 \mathrm{~kg} / \mathrm{ha} \mathrm{P}_{2} \mathrm{O}_{5}$ provide better establishment of the intercropped pasture. Nevertheless, further studies are required to determine the degree of compatibility between the two species and the viability of intercropping. Application of growing levels of phosphorus in an intercropping system provides increase in the rates of accumulation of dry matter of Xaraés grass and accumulation of total dry matter during the first dry period postestablishment of the pasture.
\end{abstract}

Key Words: Brachiaria brizantha, fertilization, mixed pasture, Stylosanthes guianensis, tillering

\section{Introdução}

Enquanto o nitrogênio (N) é considerado o elemento chave na manutenção e persistência de uma pastagem, o fósforo (P) tem sua maior relevância no estabelecimento, já que nessa situação específica as plantas necessitam de elevada disponibilidade desse elemento no solo (Malavolta et al., 1974). O fósforo (P) é essencial para desenvolvimento do sistema radicular e perfilhamento, uma vez que sua deficiência reduz a capacidade produtiva das pastagens 
(Guss et al., 1990). Além disso, é um nutriente fundamental para os processos de nodulação e fixação do nitrogênio atmosférico $\left(\mathrm{N}_{2}\right)$ (Chaudhary \& Fujita, 1998).

As leguminosas forrageiras capazes de fixar o $\mathrm{N}_{2}$, noduladas por bactérias do gênero Rhizobium, podem contribuir de forma significativa para a adição desse nutriente às pastagens, aumentando seu potencial produtivo e reduzindo a necessidade de fertilizantes nitrogenados. Além de melhorar a qualidade da dieta colhida pelo animal, devido ao maior aporte proteico, as leguminosas apresentam menor variação estacional no seu valor nutritivo em comparação às gramíneas forrageiras tropicais.

Diversos fatores, tanto das plantas como ambientais, podem influenciar o balanço entre espécies num pasto consorciado, contribuindo para alterar a persistência e a proporção dos componentes do consórcio. Entre esses fatores, um dos mais importantes é a competição pelos nutrientes disponíveis no solo.

Para o estabelecimento de uma pastagem, a população de plantas, que inicialmente depende do valor cultural da semente e da taxa de semeadura, é um fator determinante. Entretanto, as condições climáticas e a fertilidade do solo são fatores complementares e de igual importância.

A predominância de respostas lineares da produção de matéria seca (MS) ao fósforo é uma evidência de alta exigência pelas leguminosas forrageiras para expressão de seu potencial máximo de crescimento na fase inicial do estabelecimento (Guss, 1988).

Considerando que uma das dificuldades para se obterem boas consorciações é a mistura de espécies com diferentes exigências nutricionais, realizou-se este trabalho com o objetivo de avaliar o efeito da aplicação de doses crescentes de fósforo na implantação de pasto consorciado de estilosantes Mineirão (Stylosanthes guianensis cv. Mineirão) e capim-xaraés (Brachiaria brizantha cv. Xaraés).

\section{Material e Métodos}

O experimento foi conduzido no Departamento de Zootecnia da Universidade Federal de Lavras, Minas Gerais, em solo classificado como Latossolo Vermelho distrófico típico de textura muito argilosa (70\% de argila). Com base na análise do solo (Tabela 1), procedeu-se à calagem três meses antes da semeadura, objetivando elevar a saturação por bases do solo para $60 \%$, conforme recomendações de Ribeiro et al. (1999).

O experimento foi instalado em uma área de $8.000 \mathrm{~m}^{2}$, dividida em 24 parcelas experimentais de $333,3 \mathrm{~m}^{2}$ (11 m $\times$ $30,3 \mathrm{~m}$ ). O delineamento experimental utilizado foi em blocos casualizados com três repetições e com os tratamentos duas vezes dentro de cada bloco. Os tratamentos foram representados pelas doses de $\mathrm{P}_{2} \mathrm{O}_{5}(25,50,100$ e $200 \mathrm{~kg} / \mathrm{ha})$ aplicadas na semeadura.

Em novembro de 2007, procedeu-se à aplicação dos fertilizantes fosfatados nos sulcos de plantio, com espaçamento de $50 \mathrm{~cm}$ entre linhas. As fontes de fósforo utilizadas foram os superfosfatos triplo e simples. O objetivo de se utilizarem duas fontes solúveis de fósforo foi facilitar o balanceamento no suprimento de enxofre (S), completado com gesso agrícola para fornecer uma dose de $50 \mathrm{~kg} / \mathrm{ha}$.

As doses de fósforo utilizadas no estabelecimento foram 25, 50, 100 e $200 \mathrm{~kg} /$ ha de $\mathrm{P}_{2} \mathrm{O}_{5}$ e foram escolhidas de modo a permitir a avaliação das forrageiras em condições de atendimento ou não de suas exigências para estabelecimento. Com base na textura do solo da área experimental e no teor de fósforo inicialmente disponível, as recomendações são de $90 \mathrm{~kg} /$ ha de $\mathrm{P}_{2} \mathrm{O}_{5}$ para o capim-xaraés (Vilela et al., 2002) e $60 \mathrm{~kg} / \mathrm{ha}$ de $\mathrm{P}_{2} \mathrm{O}_{5}$ para o estilosantes Mineirão (Empresa Brasileira de Pesquisa Agropecuária - Embrapa, 1993). Juntamente com o fósforo, foram aplicados $40 \mathrm{~kg} / \mathrm{ha}$ de FTE BR-12 para o fornecimento de micronutrientes. Não foi necessária a aplicação de uma fonte de potássio, já que, pela análise do solo da área experimental, verificou-se adequada disponibilidade deste nutriente.

Após a aplicação do fósforo e dos micronutrientes, realizou-se a semeadura da gramínea e da leguminosa em linhas alternadas. Utilizaram-se, para a gramínea e a leguminosa 3,8 e 3,5 kg/ha de sementes puras viáveis (SPV), respectivamente. Os valores culturais (VC) registrados para os lotes de sementes, a gramínea ea leguminosa foram de $32 \%$ e $85 \%$, respectivamente. Foram aplicados em cobertura $50 \mathrm{~kg} / \mathrm{ha}$ de $\mathrm{N}$ como sulfato de amônio 30 dias após a semeadura das forrageiras.

Tabela 1 - Caracterização química do solo na camada de 0 a 20 cm antes e três meses após a aplicação do corretivo

\begin{tabular}{|c|c|c|c|c|c|c|c|c|c|c|c|c|c|}
\hline \multirow{2}{*}{$\begin{array}{l}\overline{\mathrm{pH}} \\
\mathrm{H}_{2} \mathrm{O}\end{array}$} & $\mathrm{P}$ & $\mathrm{K}$ & $\mathrm{Ca}^{2+}$ & $\mathrm{Mg}^{2+}$ & $\mathrm{Al}^{3+}$ & $\mathrm{H}+\mathrm{Al}$ & $\mathrm{SB}$ & $(\mathrm{t})$ & $(\mathrm{T})$ & $\mathrm{V}$ & $\mathrm{m}$ & MO & \multirow{2}{*}{$\begin{array}{c}\text { P-rem } \\
\text { mg/L }\end{array}$} \\
\hline & \multicolumn{2}{|c|}{$\mathrm{mg} / \mathrm{dm}^{3}$} & \multicolumn{7}{|c|}{ cmolc/dm ${ }^{3}$} & \multicolumn{3}{|c|}{$\%$} & \\
\hline \multicolumn{14}{|c|}{ Antes da aplicação do corretivo } \\
\hline \multicolumn{14}{|c|}{ Após aplicação do corretivo } \\
\hline 6,1 & 2,8 & 101 & 2,3 & 0,9 & 0 & 2,9 & 3,5 & 3,5 & 6,4 & 54,4 & 0 & 3,3 & 16 \\
\hline
\end{tabular}


Aos 65 dias após a semeadura, realizou-se em todas as parcelas a seleção de duas subamostras de $1 \mathrm{~m}^{2}$, tomadas ao acaso para a realização de avaliações não-destrutivas da pastagem em estabelecimento. Em cada subamostra foram escolhidos, também ao acaso, e marcados cinco perfilhos da gramínea e quatro plantas da leguminosa para avaliação.

As características avaliadas nos perfilhos marcados do capim-xaraés foram comprimento da última lâmina foliar completamente expandida (com a lígula exteriorizada), largura da última lâmina foliar completamente expandida, tomada perpendicularmente à nervura central e na porção mediana da respectiva lâmina, número total de folhas com a lígula exteriorizada (vivas, senescentes e mortas) e altura de perfilhos, medida da superfície do solo até a lígula da última folha completamente expandida. As características avaliadas nas plantas marcadas do estilosantes Mineirão foram: comprimento de folíolos, obtido pela média dos folíolos centrais da segunda e terceira folhas, a partir da extremidade superior da planta; largura de folíolos, tomada perpendicularmente à nervura central e no meio dos mesmos folíolos usados para a medida do comprimento e altura do estilosantes; medida da superfície do solo até a inserção da última folha no caule da planta. Ainda, procedeu-se à contagem do número de perfilhos (densidade de perfilhos) do capim-xaraés e do número de plantas do estilosantes Mineirão nas mesmas áreas de $1 \mathrm{~m}^{2}$ delimitadas para as avaliações individuais das gramíneas e das leguminosas.

A estimativa da cobertura do solo pelas plantas da pastagem foi realizada por meio de avaliação visual utilizando-se um quadrado de $1 \times 1 \mathrm{~m}$, lançado ao acaso três vezes em cada parcela. Os valores encontrados resultaram da média aritmética de três avaliadores que atribuíram notas de 0 a $100 \%$ com intervalos percentuais mínimos de cinco unidades.

O manejo de formação da pastagem foi realizado aos 80 dias pós-semeadura, colocando-se na área experimental animais leves para o pastejo. Após o pastejo pelos animais, realizou-se uma roçada com roçadeira costal motorizada para uniformização do resíduo pós-pastejo. Após estes procedimentos, não foram mais colocados animais na área experimental.

As taxas de acúmulo de MS durante o período seco da gramínea e da leguminosa foram medidas do final de junho ao final de setembro. No mês de junho, um quadrado de $1 \times 1 \mathrm{~m}$ foi lançado três vezes ao acaso dentro de cada parcela gerando três subamostras para cada parcela. O corte da gramínea foi feito rente ao solo e o da leguminosa a $5 \mathrm{~cm}$ da superfície do solo. Uma estaca de madeira foi colocada no centro do quadrado para marcar a localização da área amostrada. Em setembro, antes do início das chuvas (Figura 1), a forragem foi novamente cortada nos locais previamente marcados. As taxas de acúmulo da gramínea e da leguminosa foram obtidas pela divisão da massa de forragem produzida pelo número de dias entre os dois cortes sucessivos.

A análise de variância dos dados foi realizada pelo programa SISVAR (Ferreira, 2008), com os efeitos das doses de fósforo sendo testados por meio de equações de regressão. Os parâmetros de regressão foram testados pelo teste $\mathrm{F}$ com significância de 1 e 5\% de probabilidade e nos seus respectivos coeficientes de determinação.

\section{Resultados e Discussão}

Observou-se efeito significativo $(\mathrm{P}<0,05)$ da adubação fosfatada sobre o comprimento e a largura de lâmina foliar do capim-xaraés (Figura 2). O comprimento da lâmina foliar do capim-xaraés aumentou intensamente no intervalo entre 25 e $50 \mathrm{~kg} /$ ha de $\mathrm{P}_{2} \mathrm{O}_{5}$. A partir dessa dose, o efeito da adubação fosfatada foi menos pronunciado. Entretanto, o comprimento da lâmina foliar continuou favorecido pela adubação fosfatada até a dose de $200 \mathrm{~kg} /$ ha de $\mathrm{P}_{2} \mathrm{O}_{5}$. O efeito da adubação fosfatada sobre a largura da lâmina foliar foi mais marcante no intervalo entre 25 e $100 \mathrm{~kg} / \mathrm{ha} \mathrm{de} \mathrm{P}_{2} \mathrm{O}_{5}$. No intervalo entre 100 e $200 \mathrm{~kg} / \mathrm{ha}$ de $\mathrm{P}_{2} \mathrm{O}_{5}$, o aumento da largura da lâmina foliar reduziu em resposta à adubação fosfatada.

Esses resultados possivelmente decorrem de limitações no suprimento de nitrogênio, visto que esse nutriente, ao estimular a produção de novas células, possibilita aumento na taxa de alongamento de folhas, o que pode proporcionar mudanças no tamanho da lâmina foliar (Garcez Neto et al., 2002). Pode-se inferir que o nitrogênio mineral aplicado no estabelecimento, somado ao nitrogênio do solo proveniente da mineralização da matéria orgânica, não foram suficientes para provocar crescimento foliar inicial diferenciado do

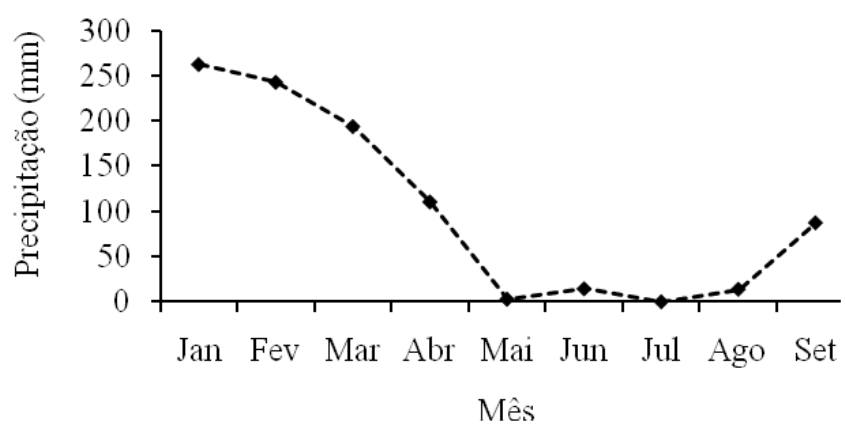

Figura 1 - Médias de precipitação pluviométrica dos meses de janeiro a setembro de 2008 na região de Lavras, Minas Gerais. 
capim-xaraés quando houve elevação da adubação fosfatada no estabelecimento da pastagem. Entretanto, especificamente, para esta situação de consórcio entre uma gramínea e uma leguminosa, essa resposta decrescente do crescimento da lâmina foliar no estabelecimento em função de uma possível limitação de nitrogênio pode ser benéfica, já que implica em menor aumento da área foliar da gramínea e, consequentemente, favorece a captação de luz pela leguminosa.

O número de folhas por perfilho não foi influenciado $(\mathrm{P}>0,05)$ pelas doses de fósforo. $\mathrm{O}$ capim-xaraés apresentou média de 4,5 folhas por perfilho. Embora seja uma característica genotípica, o número de folhas pode ser influenciado por aspectos nutricionais, porém, de acordo com os resultados deste estudo, isoladamente o fósforo não foi capaz de influenciar essa variável. De forma semelhante ao que ocorreu neste estudo, a aplicação de doses de fósforo em níveis de 0 a $150 \mathrm{~kg} /$ ha de $\mathrm{P}_{2} \mathrm{O}_{5}$ não influenciou o número de folhas do capim-tanzânia (Panicum maximum cv. Tanzânia-1); houve efeito apenas da adubação nitrogenada (Patês et al., 2007).

A adubação fosfatada teve efeito $(P<0,05)$ sobre 0 comprimento e a largura de folíolos do estilosantes Mineirão (Figura 3). Sobre o comprimento do folíolo, o efeito das doses de fósforo foi positivo, com resposta mais acentuada

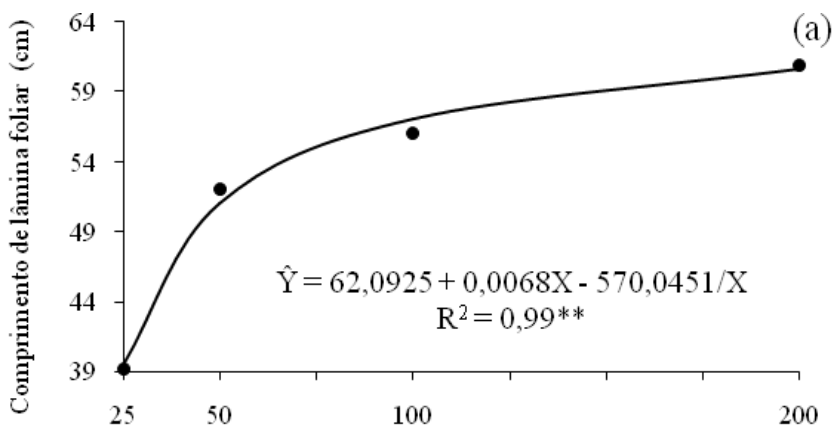

Doses de $\mathrm{P}_{2} \mathrm{O}_{5}(\mathrm{~kg} / \mathrm{ha})$

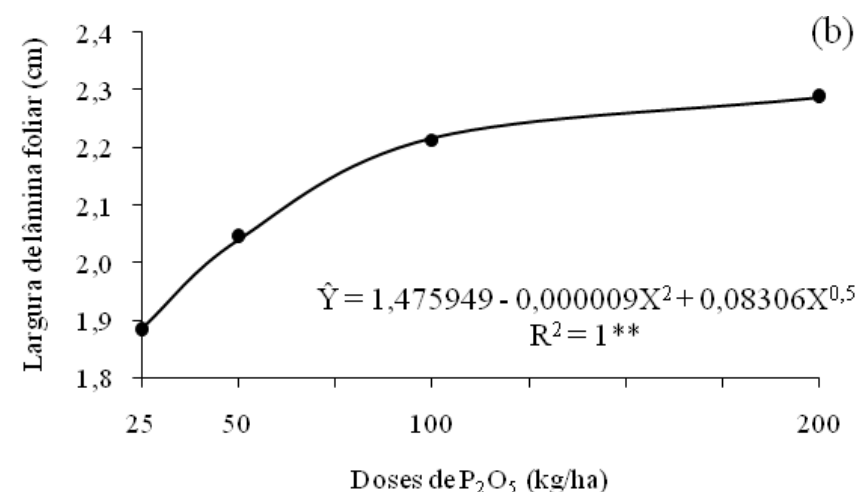

Figura 2 - Comprimento (a) e largura (b) de lâmina foliar do capim-xaraés em função das doses de $\mathrm{P}_{2} \mathrm{O}_{5}$. no intervalo entre 25 e $50 \mathrm{~kg} / \mathrm{ha}$ de $\mathrm{P}_{2} \mathrm{O}_{5}$. A partir da aplicação de $50 \mathrm{~kg} / \mathrm{ha}$ de $\mathrm{P}_{2} \mathrm{O}_{5}$, o efeito positivo da adubação sobre o comprimento do folíolo foi bem menos evidente, porém continuou ocorrendo até a dose $200 \mathrm{~kg} / \mathrm{ha}$ de $\mathrm{P}_{2} \mathrm{O}_{5}$. De forma semelhante, a largura do folíolo também foi favorecida pelas doses crescentes de $\mathrm{P}_{2} \mathrm{O}_{5}$ e o intervalo entre 25 e $50 \mathrm{~kg} /$ ha de $\mathrm{P}_{2} \mathrm{O}_{5}$ foi responsável pela maior taxa de crescimento.

Em análise conjunta do comprimento e da largura de folíolos, concluiu-se que a expansão mais acentuada da área dos folíolos e, consequentemente, da área foliar da leguminosa estudada ocorreu no intervalo entre 25 e $50 \mathrm{~kg} / \mathrm{ha}$ de $\mathrm{P}_{2} \mathrm{O}_{5}$. Especificamente no caso do estilosantes Mineirão, a baixa resposta a doses superiores a $50 \mathrm{~kg} / \mathrm{ha}$ de $\mathrm{P}_{2} \mathrm{O}_{5}$ decorre do desenvolvimento de mecanismos adaptativos desta leguminosa a situações de baixa disponibilidade deste nutriente (Barcellos et al., 2001). Desta forma, é possível atingir uma situação teto para o crescimento de folhas de estilosantes Mineirão, com doses relativamente baixas de fósforo.

A adubação fosfatada de estabelecimento influenciou $(\mathrm{P}<0,05)$ as alturas de perfilho do capim-xaraés e da planta de estilosantes Mineirão (Figura 4).

A maior taxa de crescimento de perfilhos da gramínea foi observada no intervalo de 25 a $100 \mathrm{~kg} / \mathrm{ha}$ de P2O5, com

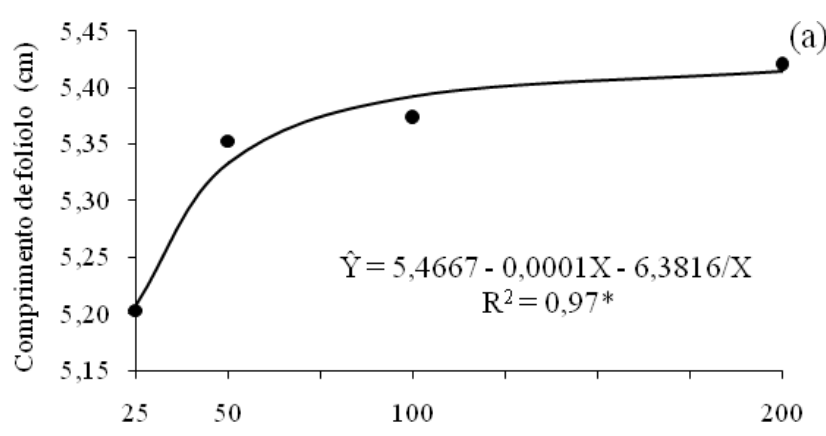

Doses de $\mathrm{P}_{2} \mathrm{O}_{5}(\mathrm{~kg} / \mathrm{ha})$

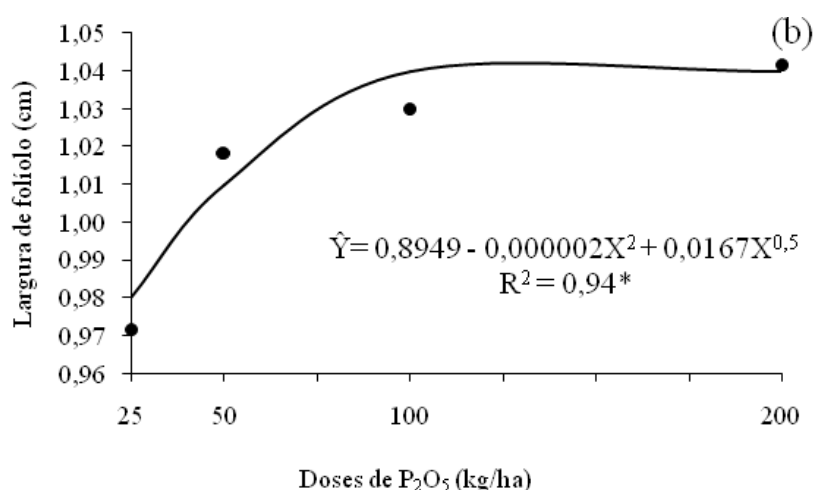

Figura 3 - Comprimento (a) e largura de folíolo (b) do estilosantes Mineirão em função das doses de $\mathrm{P}_{2} \mathrm{O}_{5}$.

R. Bras. Zootec., v.40, n.12, p.2658-2665, 2011 
posterior estabilização. Assim como ocorreu para o comprimento e a largura da lâmina foliar do capim-xaraés, é provável que a carência de nitrogênio tenha impedido que a aplicação de $200 \mathrm{~kg} / \mathrm{ha} \mathrm{de} \mathrm{P}_{2} \mathrm{O}_{5}$ proporcionasse altura muito mais elevada em relação à observada na dose $100 \mathrm{~kg} / \mathrm{ha}$ do P2O5 (Figura 2). Diferentemente do que ocorreu neste estudo, a aplicação de fósforo em doses variando de 50 a $250 \mathrm{~kg} / \mathrm{ha}$ de $\mathrm{P}_{2} \mathrm{O}_{5}$ no estabelecimento da pastagem de Brachiaria decumbens provocou aumento linear na altura da gramínea estudada (Mesquita et al., 2004). Já em outro estudo com capim-tanzânia, a aplicação de fósforo em doses de 0 a $150 \mathrm{~kg} / \mathrm{ha}$ de $\mathrm{P}_{2} \mathrm{O}_{5}$ proporcionou respostas positivas, porém não-lineares, em altura. A resposta à aplicação de fósforo melhorou quando a adubação nitrogenada aplicada passou de 100 para $200 \mathrm{~kg} / \mathrm{ha}$ (Belarmino et al., 2003). Considerando que o nitrogênio é o principal nutriente que modula o crescimento das plantas forrageiras, é possível inferir que a disponibilidade desse mineral no solo não limitou o crescimento do capim-xaraés até a dose $100 \mathrm{~kg} / \mathrm{ha}$ de $\mathrm{P}_{2} \mathrm{O}_{5}$.

Os aumentos nas doses de fósforo aplicadas proporcionaram maiores alturas do estilosantes Mineirão. A maior taxa de crescimento foi observada no intervalo de 25 a $50 \mathrm{~kg} / \mathrm{ha}$ de $\mathrm{P}_{2} \mathrm{O}_{5}$. Todavia, com base no estudo de
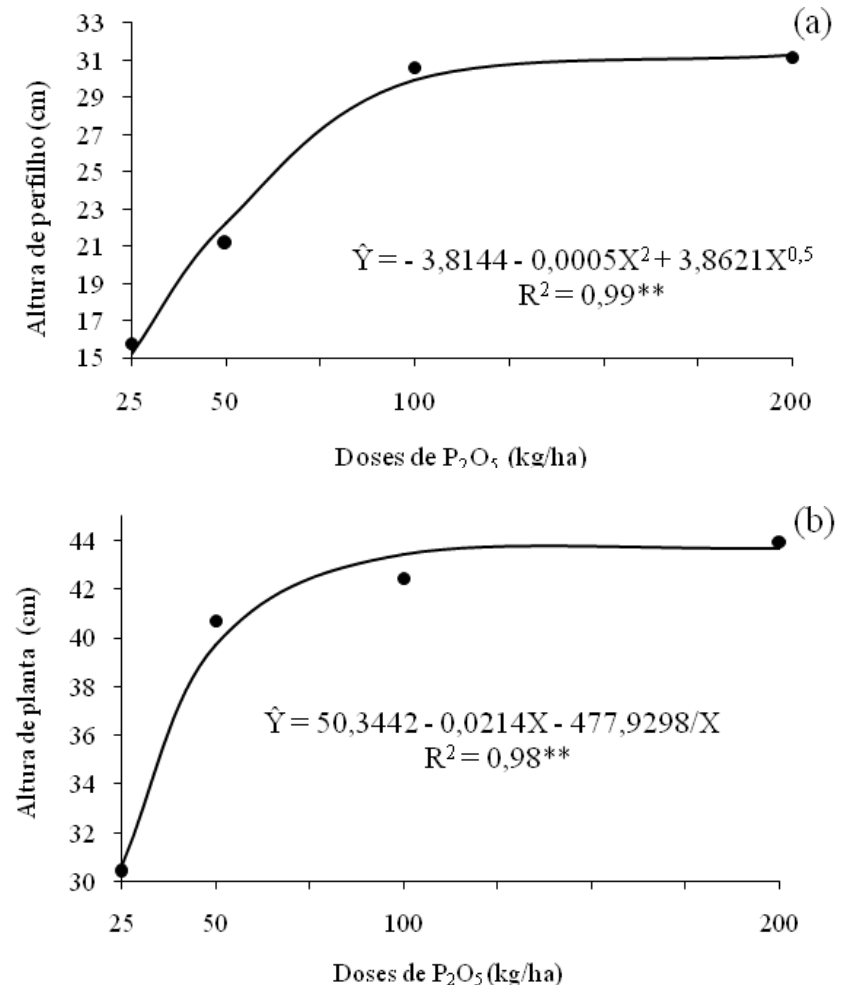

Figura 4 - Alturas de perfilho do capim-xaraés (a) e da planta de estilosantes Mineirão (b) em função das doses de $\mathrm{P}_{2} \mathrm{O}_{5}$. regressão (Figura 4b), a altura máxima do estilosantes Mineirão, de aproximadamente $44 \mathrm{~cm}$, ocorreu com a aplicação de $105 \mathrm{~kg} / \mathrm{ha}$ de $\mathrm{P}_{2} \mathrm{O}_{5}$.

Em relação a esta variável pode-se inferir que, do ponto de vista competitivo, doses acima de $50 \mathrm{~kg} / \mathrm{ha}$ de $\mathrm{P}_{2} \mathrm{O}_{5}$ prejudicariam o estabelecimento do consórcio entre estilosantes Mineirão e capim-xaraés, visto que a taxa de crescimento da leguminosa, em termos de altura seria bastante reduzida, o que certamente teria efeito direto na capacidade da planta em interceptar a radiação fotossinteticamente ativa.

Observou-se efeito $(\mathrm{P}<0,05)$ da adubação fosfatada sobre a densidade populacional de perfilhos do capimxaraés e o número de plantas de estilosantes Mineirão (Figura 5).

A adubação fosfatada teve efeito marcante sobre o perfilhamento inicial do capim-xaraés. Entretanto, a maior taxa de aumento no número de perfilhos foi observada no intervalo entre 25 e $50 \mathrm{~kg} /$ ha de $\mathrm{P}_{2} \mathrm{O}_{5}$. Esse maior aumento proporcional da dose 25 para $50 \mathrm{~kg} /$ ha de $\mathrm{P}_{2} \mathrm{O}_{5}$ é devido aos incrementos decrescentes. Nesta faixa de adubação, esse efeito foi menor que no restante do intervalo estudado, demonstrando maior resposta da planta à adubação fosfatada. Novamente, a limitação de nitrogênio pode
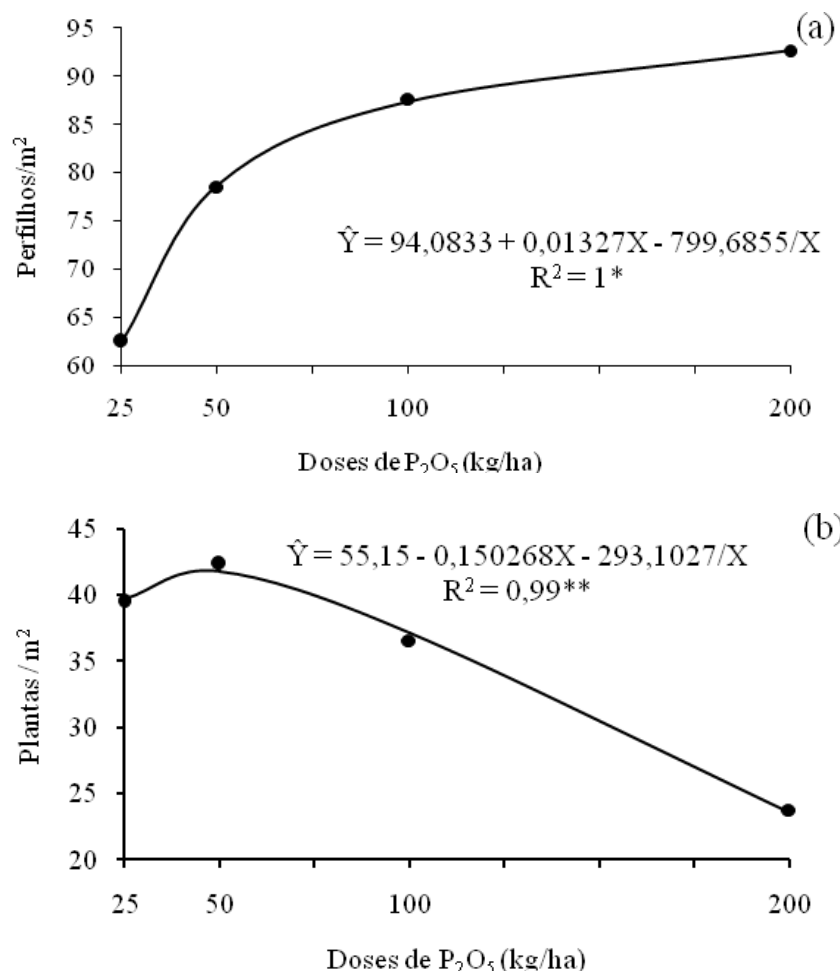

Figura 5 - Densidade populacional de perfilhos do capim-xaraés (a) e número de plantas de estilosantes Mineirão (b) em função das doses de $\mathrm{P}_{2} \mathrm{O}_{5}$.

R. Bras. Zootec., v.40, n.12, p.2658-2665, 2011 
explicar a menor variação entre as adubações com 50 e $200 \mathrm{~kg} /$ ha de $\mathrm{P}_{2} \mathrm{O}_{5}$. Esta afirmação é pautada em estudos com capim-tanzânia com doses de fósforo variando de 0 a $150 \mathrm{~kg} /$ ha de $\mathrm{P}_{2} \mathrm{O}_{5}$ em que o perfilhamento da gramínea aumentou apenas quando a adubação fosfatada esteve associada à nitrogenada (Patês et al., 2007).

A densidade populacional de perfilhos tende a aumentar até o ponto em que a competição entre as plantas torna-se tão intensa que a população se estabiliza e, para cada perfilho que nasce, ocorre a morte de outro (Corsi \& Nascimento Junior, 1994). Entretanto, especificamente para essa situação de estabelecimento de pastagem e considerando o grau de exigência da gramínea estudada, a limitação nutricional realmente é a explicação mais plausível para o resultado observado. Ressalta-se que, numa situação de consórcio, o menor perfilhamento inicial da gramínea é vantajoso, uma vez que propicia maior oportunidade para a leguminosa se estabelecer, já que esta última notoriamente tem desenvolvimento inicial mais lento.

O número máximo de plantas de estilosantes Mineirão, 42 plantas $/ \mathrm{m}^{2}$, foi observado quando o pasto foi adubado com $44 \mathrm{~kg} /$ ha de $\mathrm{P}_{2} \mathrm{O}_{5}$. É possível inferir, portanto, que essa dose de fósforo garantiu melhor ambiente para germinação, emergência e desenvolvimento inicial de plantas de estilosantes Mineirão sem, contudo, propiciar desenvolvimento da gramínea capaz de provocar competição mais acirrada com a leguminosa. A acentuada redução na população de plantas observada com doses de $\mathrm{P}_{2} \mathrm{O}_{5}$ acima de $44 \mathrm{~kg} /$ ha resulta da maior capacidade de desenvolvimento inicial do capim-xaraés em resposta à adubação fosfatada, associada ao lento desenvolvimento inicial do estilosantes Mineirão (Barcellos et al., 2008). Além das vantagens ecofisiológicas do capim-xaraés em relação ao estilosantes Mineirão, é necessário considerar o efeito alelopático da espécie Brachiaria brizantha sobre leguminosas do gênero Stylosanthes (Almeida et al., 1997). Portanto, em condições de maior suprimento de fósforo, e com possibilidades de maior desenvolvimento inicial da gramínea, a liberação de substâncias aleloquímicas pelo capim-xaraés também poderia ser bastante favorecida, aumentando o grau de inibição do desenvolvimento inicial do estilosantes Mineirão.

Observou-se efeito $(\mathrm{P}<0,05)$ da adubação fosfatada sobre a cobertura inicial do solo pelas plantas do consórcio (Figura 6).

A cobertura do solo foi favorecida pelo aumento nas doses de fósforo em todo o intervalo estudado. No entanto, aos 65 dias pós-semeadura, mesmo com a aplicação de $200 \mathrm{~kg} / \mathrm{ha}$ de $\mathrm{P}_{2} \mathrm{O}_{5}$, o solo da área da pastagem ainda não se encontrava completamente coberto. A presença de espaços abertos em pastos em formação é uma oportunidade para que espécies de plantas invasoras colonizem a área e passem a competir com as espécies forrageiras pelos fatores abióticos. Dessa forma, numa pastagem exclusiva, o grau de competição com espécies invasoras, entre outros fatores, pode ser considerado inversamente proporcional à velocidade de crescimento da espécie forrageira. Entretanto, considerando uma situação de consórcio entre gramíneas e leguminosas, um avanço mais lento na cobertura do solo pela gramínea poderia beneficiar a leguminosa na consorciação, uma vez que seu estabelecimento é mais lento que o da gramínea. Essa hipótese foi comprovada neste estudo, uma vez que na dose em que ocorreu a maior população inicial de plantas de estilosantes Mineirão (44 kg/ha $\mathrm{P}_{2} \mathrm{O}_{5}$ ), apenas $68 \%$ do solo encontrava-se coberto pelas plantas do consórcio.

Houve efeito $(\mathrm{P}<0,05)$ da adubação fosfatada sobre as taxas de acúmulo de MS (TAMS) de capim-xaraés e de MS total no primeiro período seco pós-estabelecimento do consórcio (Figura 7).

A aplicação de doses crescentes de fósforo proporcionou aumento da taxa de acúmulo de MS do capim-xaraés durante o primeiro período seco pósestabelecimento da pastagem. A elevação na taxa de acúmulo de MS foi mais marcante no intervalo de 25 a $100 \mathrm{~kg} / \mathrm{ha}$ de $\mathrm{P}_{2} \mathrm{O}_{5}$ e estabilizou-se a partir dessa dose.

A elevação na taxa de acúmulo de MS do capim-xaraés com os acréscimos da adubação fosfatada de estabelecimento comprova claramente o efeito positivo do fósforo sobre o desenvolvimento da gramínea, mesmo em condições de estresse hídrico, como ocorre no inverno da região. Além disso, o capim-xaraés é menos afetado pelo efeito estacional que outras gramíneas forrageiras tropicais, chegando a apresentar até 30\% de sua produção no período seco (Valle et al., 2001). Também é necessário considerar a

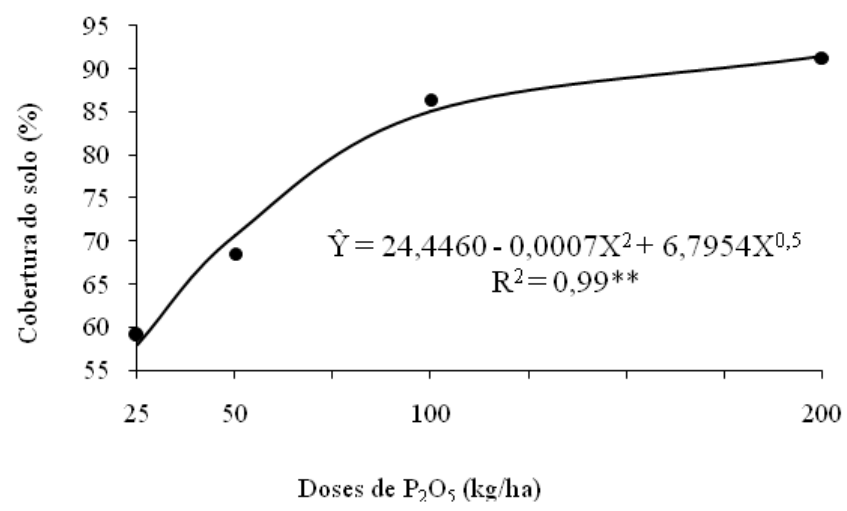

Figura 6 - Cobertura do solo pelas plantas do consórcio de capimxaraés e estilosantes Mineirão em função das doses de $\mathrm{P}_{2} \mathrm{O}_{5}$. 


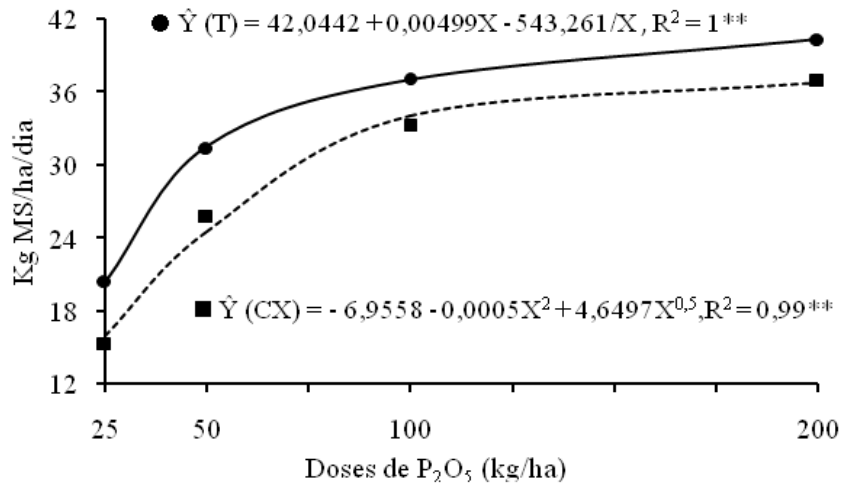

Figura 7 - Taxas de acúmulo de MS (TAMS) de capim-xaraés (CX) e de MS total (T) no primeiro período seco pósestabelecimento da pastagem consorciada.

significativa redução na população de plantas de estilosantes a partir da aplicação de $44 \mathrm{~kg} / \mathrm{ha}$ de $\mathrm{P}_{2} \mathrm{O}_{5}$, resultando em menor competição. Entretanto, a pequena variação entre as adubações com 100 e $200 \mathrm{~kg} /$ ha de $\mathrm{P}_{2} \mathrm{O}_{5}$ possivelmente resulta de deficiência de outros nutrientes, sobretudo nitrogênio, uma vez que a maior presença desse nutriente é capaz de elevar a taxa de acúmulo de MS de gramíneas mesmo em períodos secos (Fagundes et al., 2006).

A taxa de acúmulo de MS da leguminosa foi influenciada pela adubação $(\mathrm{P}<0,05)$, porém, não houve ajuste ao estudo de regressão. O valor médio observado foi de 4,46 kg/ha/dia de MS. Mesmo em condições de baixa temperatura e ausência de precipitação, o estilosantes Mineirão é capaz de manter crescimento vegetativo (Purcino et al., 2005), porém a falta de ajustamento dos dados à análise de regressão é reflexo do comportamento da população de plantas de estilosantes Mineirão em resposta aos acréscimos da adubação fosfatada, cuja variação também contribui para alterar o acúmulo de MS, e não apenas do crescimento individual de plantas da leguminosa. Portanto, a menor capacidade do Mineirão em responder aos suprimentos adicionais de fósforo, associada à redução na população de plantas com a maior agressividade da gramínea nas doses mais elevadas de fósforo, são os fatores responsáveis pelo reduzido acúmulo de MS dessa leguminosa no período seco, mesmo diante de sua elevada capacidade de resistir ao déficit hídrico.

Para a taxa de acúmulo de MS total, o maior aumento em resposta à adubação fosfatada foi verificado no intervalo entre 25 e $50 \mathrm{~kg} / \mathrm{ha}$ de $\mathrm{P}_{2} \mathrm{O}_{5}$, tendendo à estabilização posteriormente. A partir da aplicação de 44 $\mathrm{kg} / \mathrm{ha}$ de $\mathrm{P}_{2} \mathrm{O}_{5}$, em função da redução na participação da leguminosa no consórcio, o acúmulo total de matéria seca foi mais dependente da gramínea.

\section{Conclusões}

A adubação fosfatada de estabelecimento de $44 \mathrm{~kg} / \mathrm{ha}$ de $\mathrm{P}_{2} \mathrm{O}_{5}$ garante maior população inicial de plantas de estilosantes Mineirão em consórcio com o capim-xaraés. Entretanto, mais estudos são necessários para investigar o grau de compatibilidade entre as duas espécies e a viabilidade da consorciação. A aplicação de doses crescentes de fósforo no consórcio proporciona aumento nas taxas de acúmulo de matéria seca do capim-xaraés e de acúmulo de matéria seca total durante o primeiro período seco pós-estabelecimento da pastagem.

\section{Referências}

ALMEIDA, A.R.P.; LUCCHESI, A.A.; ABBADO, M.R. Efeito alelopático de espécies de Brachiaria Griseb. sobre algumas leguminosas forrageiras tropicais. II. Avaliações em casa de vegetação. Boletim de Indústria Animal, v.54, n.2, p.55-64, 1997.

BARCELLOS, A.O.; ANDRADE, R.P.; KARIA, C.T. et al. Potencial e uso de leguminosas forrageiras dos gêneros Stylosanthes, Arachis e Leucaena. In: SIMPÓSIO SOBRE MANEJO DA PASTAGEM, 17., 2001, Piracicaba. Anais... Piracicaba: FEALQ, 2001. p.297-357.

BARCELlOS, A.O.; RAMOS, A.K.B.; VILELA, L. et al. Sustentabilidade da produção animal baseada em pastagens consorciadas e no emprego de leguminosas exclusivas, na forma de banco de proteína, nos trópicos brasileiros. In: REUNIÃO DA SOCIEDADE BRASILEIRA DE ZOOTENCIA, 45., 2008, Lavras. Anais... Lavras: SBZ, 2008. p.51-67.

BELARMINO, M.C.J.; PINTO, J.C.; ROCHA, G.P. et al. Altura de perfilho e rendimento de matéria seca de capim-tanzânia em função de diferentes doses de superfosfato simples e sulfato de amônio. Ciência e Agrotecnologia, v.27, n.4, p.879-885, 2003.

CHAUDHARY, M.I.; FUJITA, K. Comparison of phosphorus deficiency effects on the growth parameters of mashbean, mungbean, and soybean. Soil Science and Plant Nutrition, v.44, n.1, p.19-30, 1998.

CORSI, M.; NASCIMENTO JUNIOR, D. Princípios de fisiologia e morfologia de plantas forrageiras aplicados ao manejo das pastagens. In: PEIXOTO, A.M. MOURA, J.C.; FARIA, F.P. (Eds.). Pastagens: fundamentos da exploração racional. Piracicaba: FEALQ, 1994. p.15-48.

EMPRESA BRASILEIRA DE PESQUISA AGROPECUÁRIA. Centro Nacional de Pesquisa dos Cerrados. Recomendações para estabelecimento e utilização do Stylosanthes guianensis cv. Mineirão. Planaltina: Embrapa Cerrados, 1993. 6p. (Comunicado Técnico, 49).

FAGUNDES, L.J.; FONSECA, D.M.; MORAIS, R.V. et al. Avaliação das características estruturais do capim-braquiária em pastagens adubadas com nitrogênio nas quatro estações do ano. Revista Brasileira de Zootecnia, v.35, n.1, p.30-37, 2006.

FERREIRA, D.F. SISVAR: um programa para análises e ensino de estatística. Revista Symposium, v.6, p.36-41, 2008.

GARCEZ NETO, A.F.; NASCIMENTO JUNIOR, D.; REGAZZI, A.J. et al. Respostas morfogênicas e estruturais de Panicum maximum cv. Mombaça sob diferentes níveis de adubação nitrogenada e alturas de corte. Revista Brasileira de Zootecnia, v.31, n.5, p.1890-1900, 2002.

GUSS, A. Exigência de fósforo para estabelecimento de gramíneas e leguminosas forrageiras tropicais em solos 
com diferentes características físicas e químicas. 1988. 74f. Tese (Doutorado em Zootecnia) - Universidade Federal de Viçosa, Viçosa, MG.

GUSS, A.; GOMIDE, J.A.; NOVAIS, R.F. Exigências de fósforo para estabelecimento de quatro leguminosas forrageiras em solos com distintas características físico químicas. Revista Brasileira de Zootecnia, v.19, p.450-458, 1990.

MALAVOLTA, E.; HAAG, H.P.; MELLO, F.A.F. Nutrição mineral e adubação de plantas cultivadas. São Paulo: Pioneira, 1974. 727p.

MESQUITA, E.E.; FONSECA, D.M.; PINTO, J.C. et al. Estabelecimento de pastagem consorciada com aplicação de calcário, fósforo e gesso. Ciência e Agrotecnologia, v.28, n.2, p.428-436, 2004.

PATÊS, N.M.S.; PIRES, A.J.V.; SILVA, C.C.F. et al. Características morfogênicas e estruturais do capim-tanzânia submetido a doses de fósforo e nitrogênio. Revista Brasileira de Zootecnia, v.36, n.6, p.1736-1741, 2007.
PURCINO, H.M.A.; BARCELOS, A.O.; VERZIGNASSI, J.R. et al. Utilização e contribuição de leguminosas na produção animal. Informe Agropecuário, v.26, n.226, p.76-96, 2005.

RIBEIRO, A.C.; GUIMARÃES, P.T.G.; ALVAREZ, V.V.H. (Ed.). Recomendação para o uso de corretivos e fertilizantes em Minas Gerais: 5. aproximação. Viçosa, MG: Comissão de Fertilidade do Solo do Estado de Minas Gerais, 1999. $359 \mathrm{p}$.

VALLE, C.B.; EUCLIDES, V.P.B.; MACEDO, M.C.M. et al. Selecting new Brachiaria for Brazilian pastures. In: INTERNATIONAL GRASSLAND CONGRESS, 19., 2001, São Pedro. Proceedings... Piracicaba: Fealq, 2001. p.535-537.

VILELA, L.; SOARES, W.V.; SOUSA, D.M.G. et al.Calagem e adubação para pastagens. In: SOUSA, D.M.G.; LOBATO, E. (Eds.) Cerrado: correção do solo e adubação. Planaltina: Embrapa Cerrados, 2002. p.367-382. 